\title{
O vento e o arpão ou as regras do jogo: A pesca artesanal do pirarucu na ilha de São Miguel, Santarém-Pa
}

\author{
Roberth Rodrigues Ferreira ${ }^{1}$
}

Artigo recebido em: 12 de novembro de 2017.

Artigo aprovado em: 16 de novembro de 2017.

Vivendo no ambiente de várzea, cercados pelas águas do rio Amazonas, as sociedades ribeirinhas construíram um modo de vida centrado na atividade da pesca, seja para dieta alimentar ou garantia de renda das famílias. Variadas são as formas de exercício dessa atividade na várzea santarena. Contudo, devido à grande pressão nos lagos, algumas comunidades criaram regras de controle e defesa dos seus ambientes de pesca impedindo a entrada de pescadores de fora e delimitando que tipo de apetrecho de pesca poderia ser usado (MCGRATH et al., 1991; CASTRO e MCGRATH, 2001; RUFFINO, 2005, OVIEDO et al., 2015).

Um dos cenários de autorregulação e controle dos lagos no município de Santarém é a comunidade Ilha de São Miguel onde os seus moradores após sofrerem com a exploração desordenada e exaurimento das espécies de pescado, resolvem criar um acordo de pesca regulando a pesca, quem poderia exercê-la e em quais condições (FERREIRA, 2014).

O objetivo desse ensaio é apresentar a pesca como reguladora do modo de vida dos moradores da comunidade Ilha de São Miguel, localizada nas proximidades da margem esquerda do Rio Amazonas, na microrregião do Aritapera do município de Santarém, Estado do Pará, que por meio do acordo de pesca local e do manejo do pirarucu mantém os seus lagos preservados e consequentemente garantem a subsistências das famílias ali residentes.

Nessa perspectiva realizei três viagens de campo, com fins etnográficos, nos meses de julho, setembro e outubro de 2017, objetivando compreender como a ação coletiva torna a atividade da pesca determinante para a organização social do grupo ali residente

\footnotetext{
${ }^{1}$ Graduado em Geografia pela Universidade Federal do Oeste do Pará (ICED) e Mestrando no Programa de Pós-Graduação em Sociedade, Ambiente e Qualidade de Vida - CFI na Universidade Federal do Oeste do Pará. Bolsista da CAPES. E-mail: roberthrodrigues23@hotmail.com
} 
a partir da necessidade de proteger e preservar o pescado, seu principal meio de subsistência.

As fotografias selecionadas são o resultado que me fez querer desvendar o que venho a chamar de "reino encantado da pesca". Estas representam diferentes visões da pesca vivenciadas durante a minha permanência no campo, representando as formas de realização desta atividade, bem como as diversas ações estabelecidas pelos Filhos da Ilha ${ }^{2}$ para manter a sustentabilidade local.

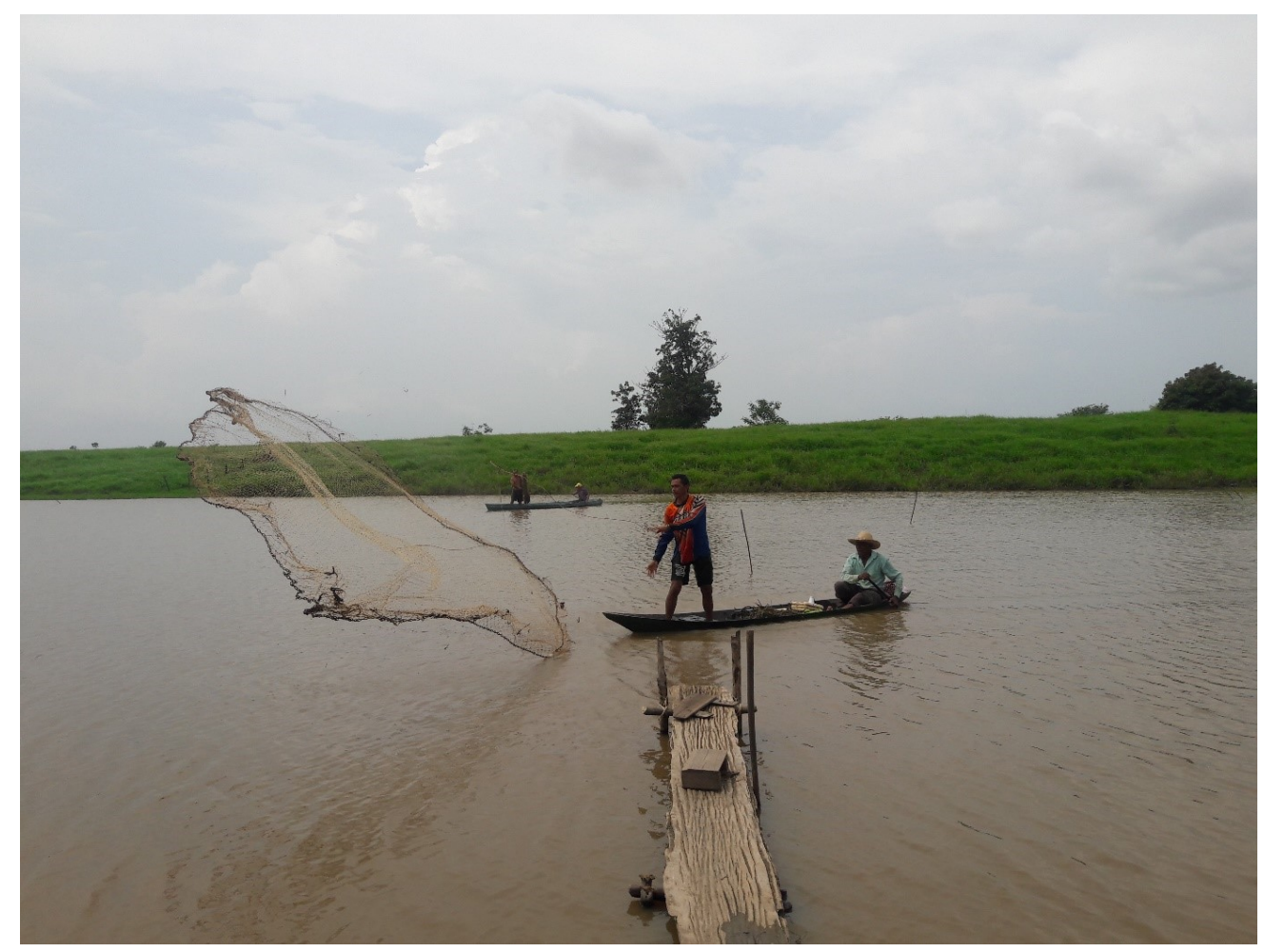

Figura 1. As pescarias com tarrafa nos lagos da llha de São Miguel são destinadas para garantir o alimento das famílias.

\footnotetext{
2É uma designação que os moradores da llha de São Miguel dão àqueles que nasceram no espaço da comunidade.
} 


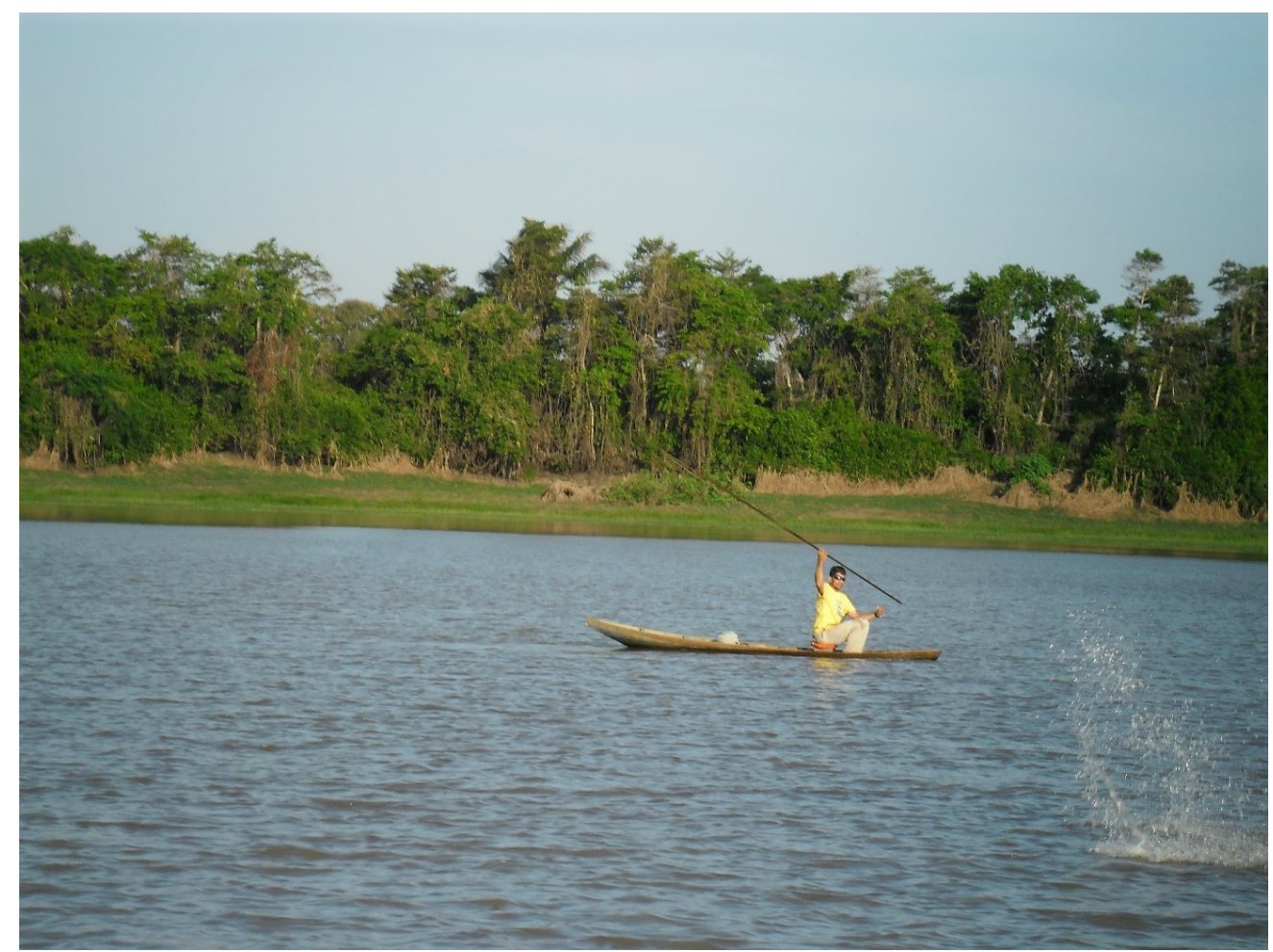

Figura 2. As pescarias do Pirarucu são realizadas utilizando como instrumento de pesca a haste/arpão

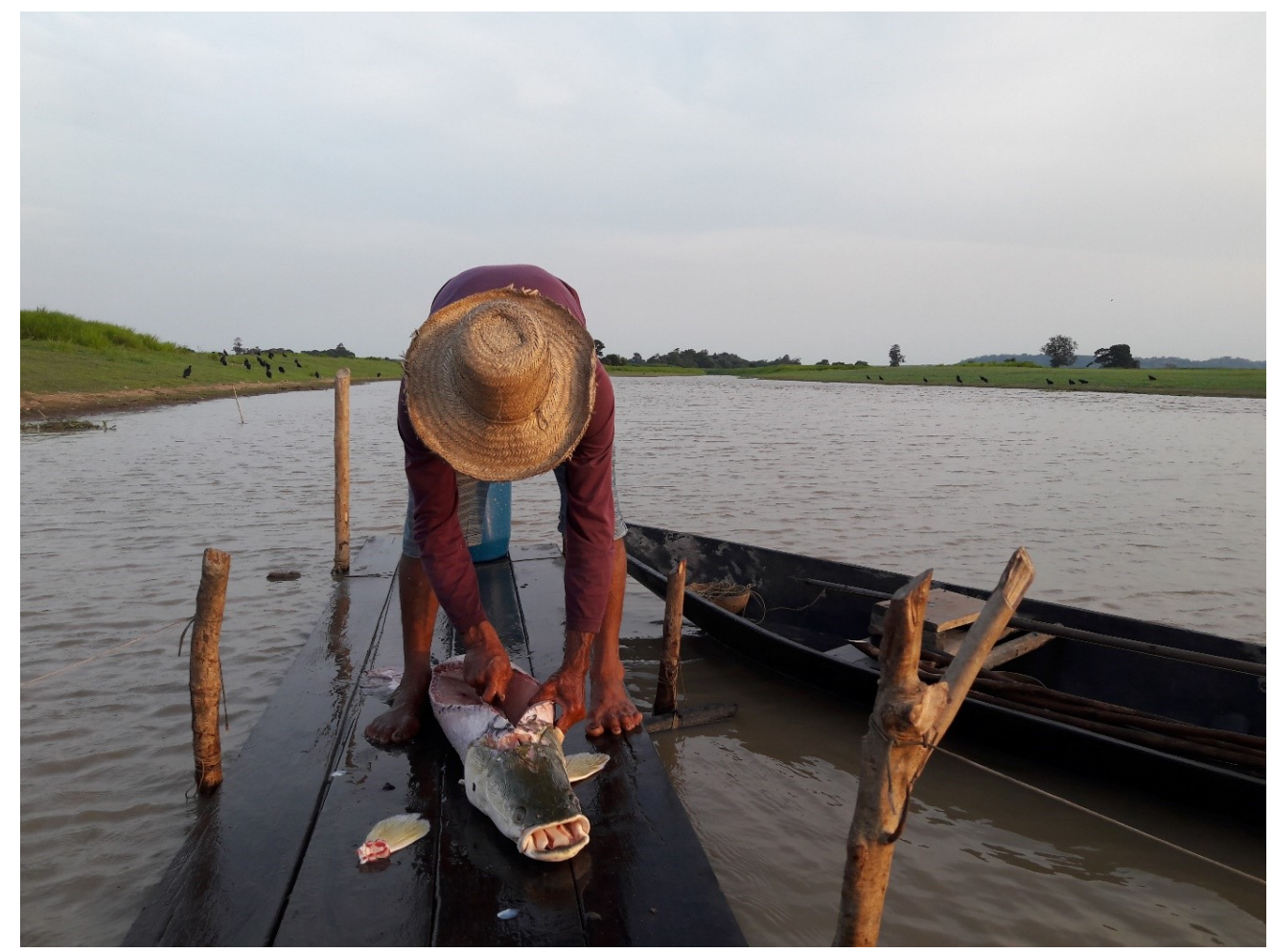

Figura 3. O pirarucu é o único espécime de pescado destinado a comercialização na llha de São Miguel. 


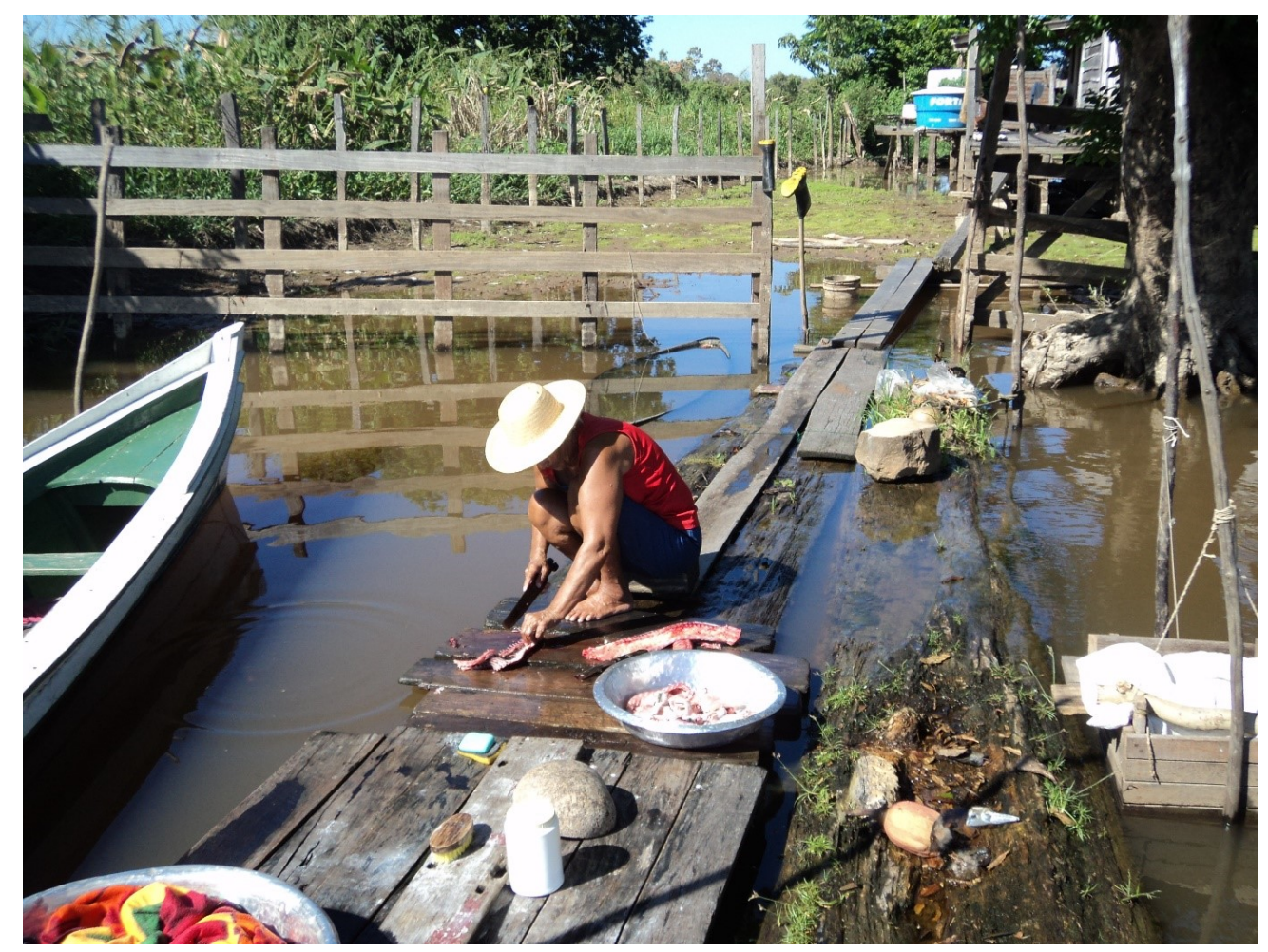

Figura 4. Além de fonte de renda o pirarucu é base alimentar dos Filhos da llha.

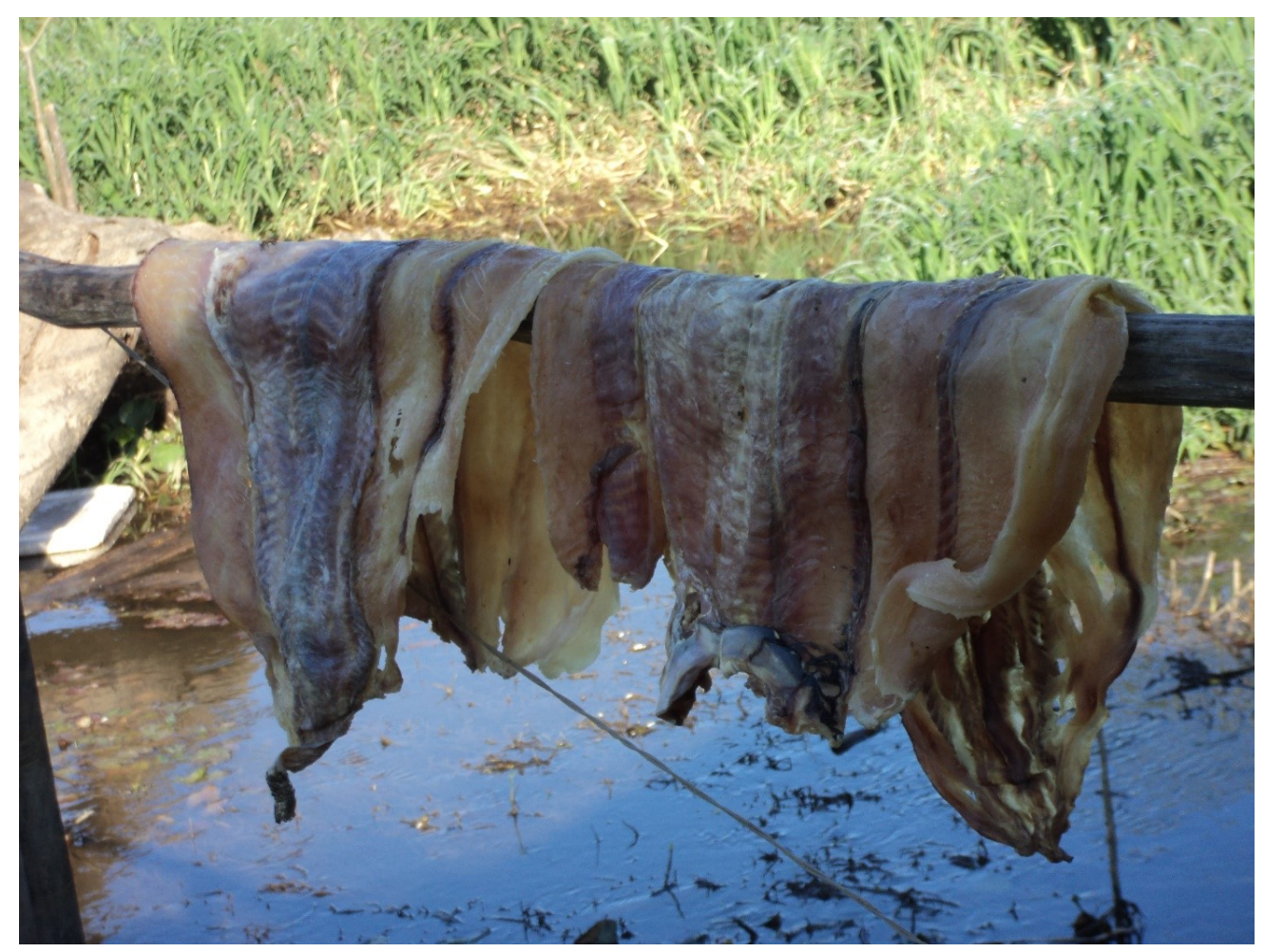

Figura 5. Como medida preventiva os comunitários secam o peixe para comer no período da cheia. 


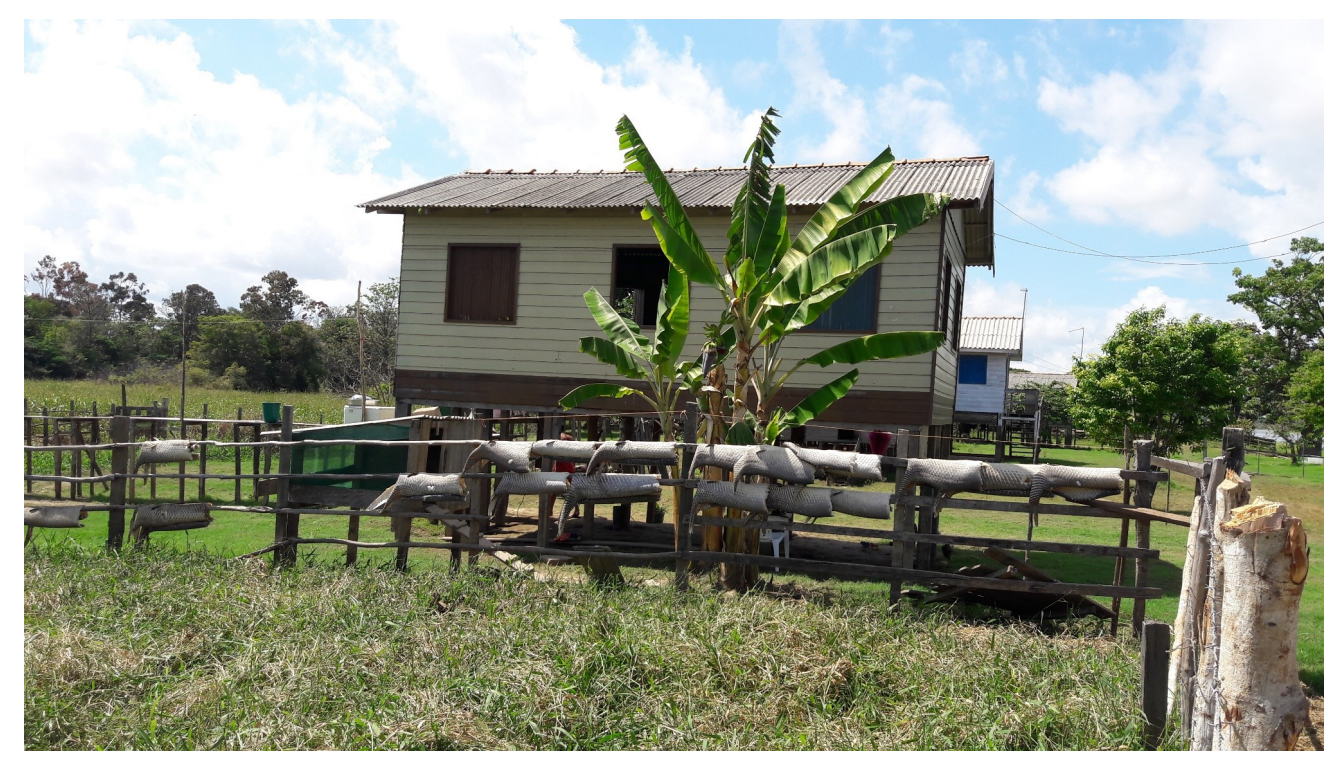

Figura 6. As escamas (couro) do pirarucu são exibidas nas cercas das casas como verdadeiros troféus dos pescadores.

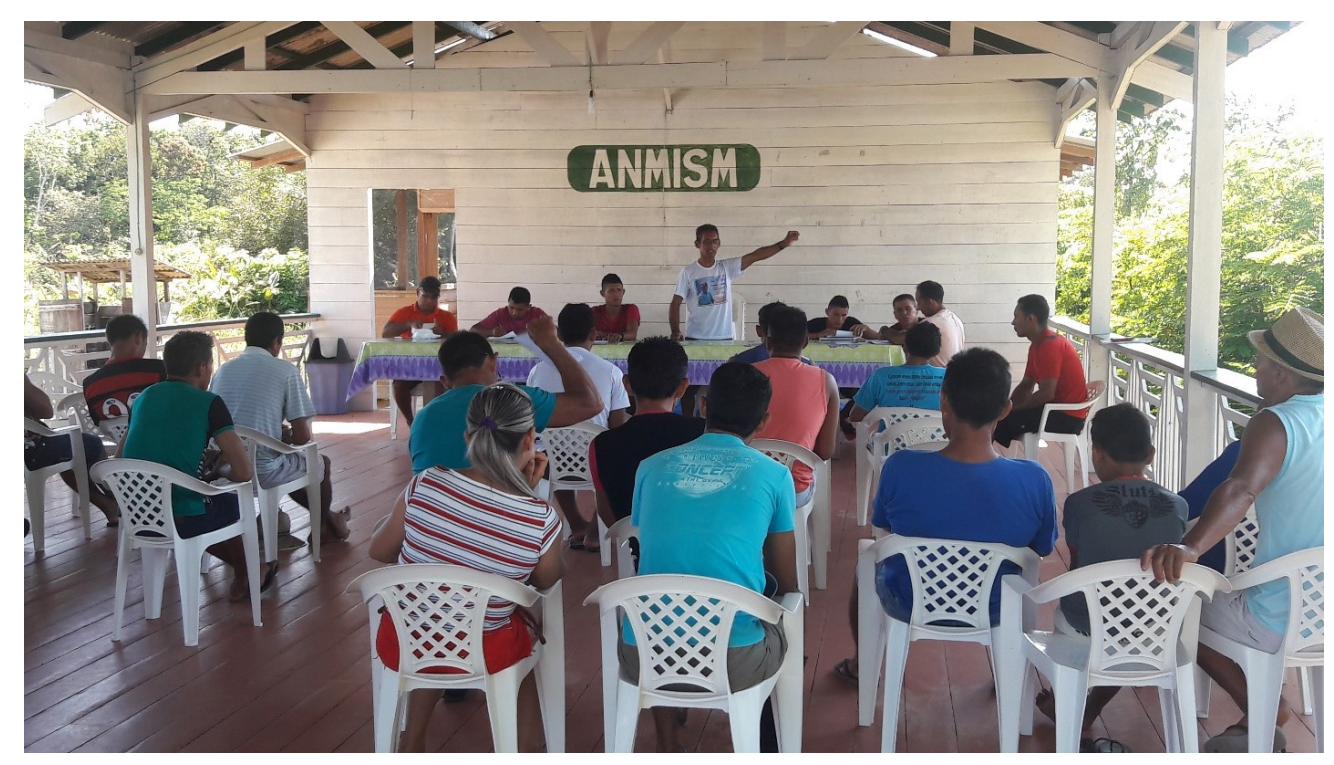

Figura 7. É na reunião comunitária que os moradores tomam medidas para o controle da pesca nos lagos da comunidade. 


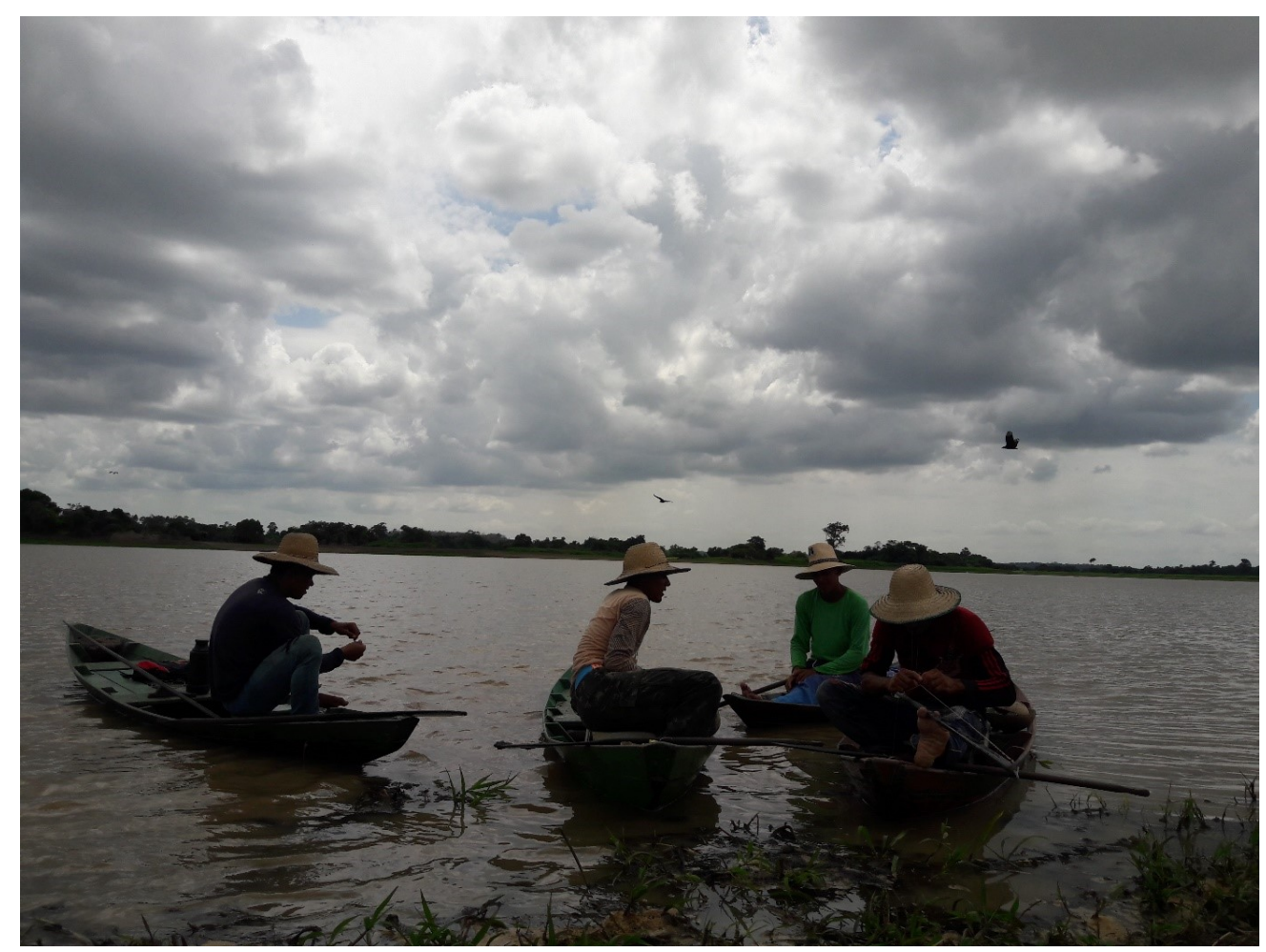

Figura 8. As conversas no lago também são momentos de avaliação da realização e situação da pesca na comunidade.

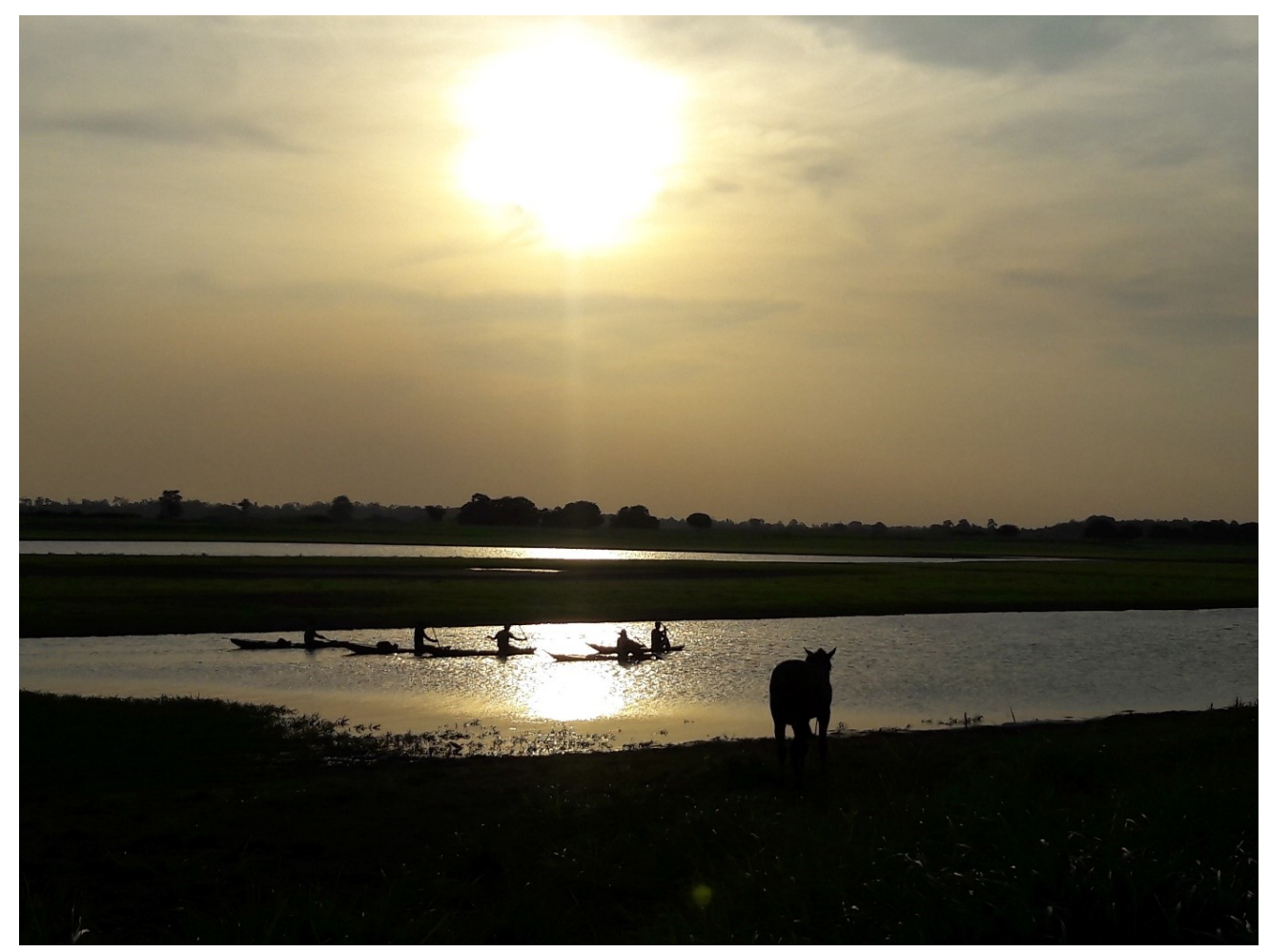

Figura 9. A fiscalização é feita por equipes de pescadores que percorrem os lagos da comunidade objetivando proibir a entrada de pescadores de fora da llha. 


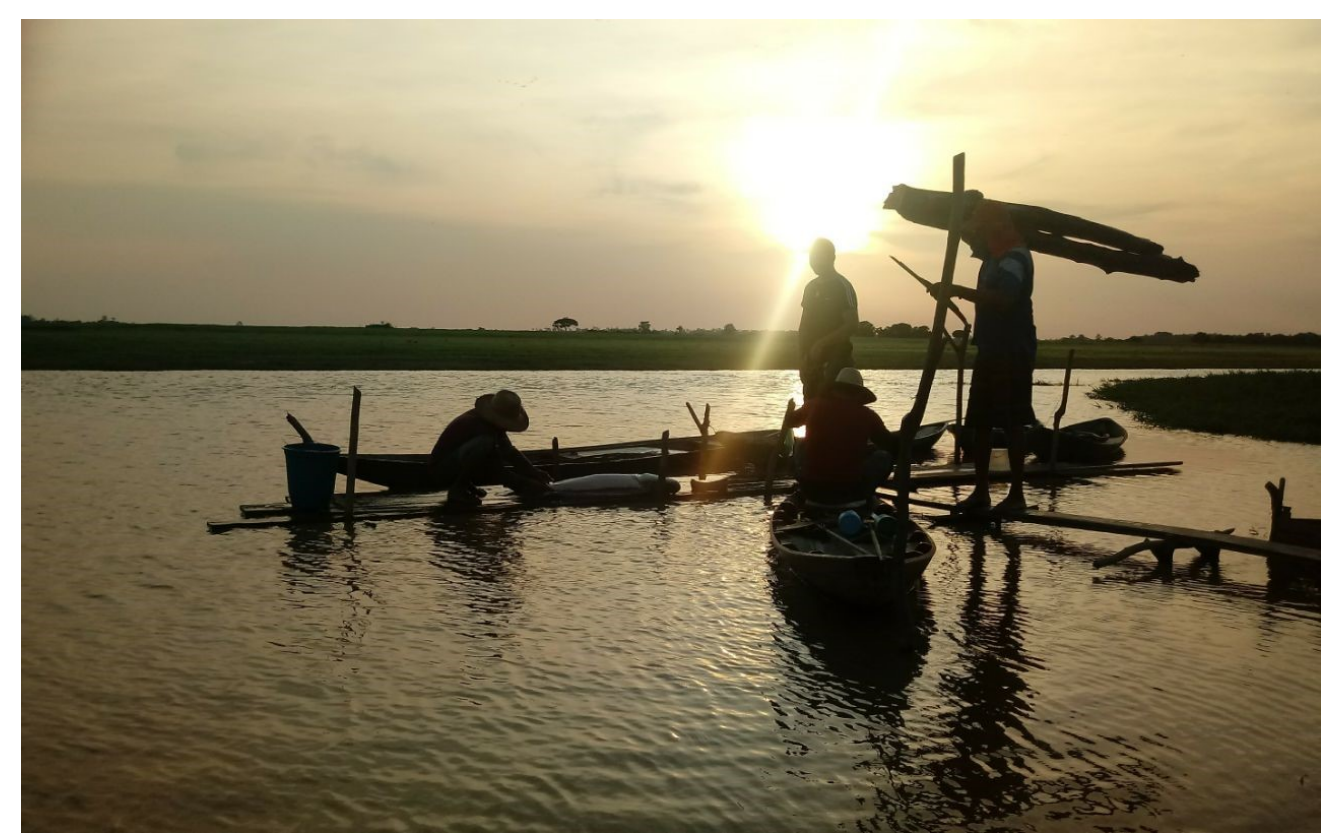

Figura 10. As estratégias de uso e controle dos lagos na llha de São Miguel possibilitaram uma gestão da pesca garantindo qualidade de vida e sustentabilidade das famílias.

\section{Referências}

CASTRO, Fábio de; McGrath, David. O manejo comunitário de lagos na Amazônia. Parcerias Estratégicas. Brasília, $\mathrm{n}^{\circ} 12$ - setembro de 2001. p. 112 - 126. Disponível em: <http://seer.cgee.org.br/index.php/parcerias_estrategicas/article/viewFile/179/173>. Acesso em 12 de setembro de 2017.

FERREIRA, Roberth Rodrigues. Gênero de vida e recursos de uso comum: um estudo da comunidade Ilha de São Miguel - Santarém, Pará. Trabalho de Conclusão de Curso - Licenciatura Plena em Geografia / Universidade Federal do Oeste do Pará. Santarém, ICED / UFOPA, 2014, 95p.

McGRATH, David et al. Varzeiros, geleiros e o manejo dos recursos naturais na várzea do Baixo Amazonas. Papers do NAEA. Belém, $n^{\circ}$ 004, 1991. p. 01-25. Disponível em: <http://www.naea.ufpa.br/naea/novosite/index.php?action=Publicacao.arquivo\&id=58>. Acesso em 14 setembro de 2017.

OVIEDO, Antonio Francisco Perrone; BURSZTYN, Marcel; DRUMMOND, José Augusto. Agora sob nova administração: Acordos de Pesca nas Várzeas da Amazônia Brasileira. Ambiente \& Sociedade. São Paulo, v. XVIII, n. 4, 2015. p. 119-138. Disponível em: <http://www.scielo.br/pdf/asoc/v18n4/1809-4422-asoc-18-04-00119.pdf>. Acesso em 10 de setembro de 2017.

RUFFINO, Mauro Luis. Gestão do uso dos recursos pesqueiros na Amazônia. Manaus: IBAMA, 2005. 